\title{
15 Month follow up of African children following vaginal cleansing with benzalkonium chloride of their HIV infected mothers during late pregnancy and delivery
}

\author{
L Mandelbrot, P Msellati, N Meda, V Leroy, R Likikouët, P Van de Perre, \\ L Dequae-Merchadoux, F Sylla-Koko, A Ouangre, T Ouassa, R Ramon, \\ L Gautier-Charpentier, M Cartoux, M Dosso, F Dabis, C Welffens-Ekra, for the ANRS \\ 049 Ditrame Study Group*
}

See end of article for authors' affiliations

Correspondence to: Dr Laurent Mandelbrot, Hopital Cochin, Port Royal, 123 Bd de Port Royal, 75014 Paris, France; laurent.mandelbroł@ bch.ap-hop-paris.fr

Accepted for publication 9 May 2002

\begin{abstract}
Objectives: To study mother to child HIV-1 transmission (MTCT) and infant mortality following benzalkonium chloride $(\mathrm{BC})$ disinfection.

Methods: A randomised, double blind phase II placebo controlled trial. Women testing positive for HIV-1 infection in prenatal care units in Abidjan, Côte d'Ivoire, and Bobo-Dioulasso, Burkina Faso, from November 1996 to April 1997 were eligible, with their informed consent. Women self administered daily a vaginal suppository of $1 \% \mathrm{BC}(53)$ or matched placebo (54) from 36 weeks of pregnancy, plus a single dose during labour. The neonate was bathed with $1 \% \mathrm{BC}$ solution or placebo within $30 \mathrm{~min}$ utes after birth. MTCT rate was assessed based on repeated polymerase chain reaction (PCR) and serology results. For the present analysis, children were followed up to 15 months.

Results: A total of 107 women were enrolled. Of 103 eligible liveborn children, 23 were HIV infected, 75 uninfected, and five of indeterminate status. MTCT transmission rate was $24.2 \%$ overall $195 \%$ confidence interval (Cl): $14.3 \%$ to $30.4 \%$ ). On an intent to treat basis, the transmission rate did not differ between the two groups $(23.5 \%, \mathrm{Cl} 13.8$ to 38.5 , in the $\mathrm{BC}$ group and $24.8 \%, \mathrm{Cl} 15.0$ to 39.6 , in the placebo group at 15 months). Similarly, there was no difference in mortality at 15 months $(22.9 \%, \mathrm{Cl}$ 13.7 to 36.9 , in the $\mathrm{BC}$ group and $16.5 \%, \mathrm{Cl} 9.0$ to 29.4 , in the placebo group).

Conclusion: This analysis failed to suggest any benefit of $B C$ disinfection on mother to child HIV transmission or perinatal and infant mortality.
\end{abstract}

$\mathrm{R}$ emarkable progress has been made over the past decade in the prevention of mother to child transmission (MTCT) of HIV-1. In developing country settings, there is a particularly crucial need for effective, safe, affordable interventions that can be sustained on a large scale. Short course antiretroviral therapies have been shown to reduce transmission by one third to one half in this context. ${ }^{1}$ Their efficacy tends to decrease with prolonged exposure to breast feeding, ${ }^{2}$ but remains highly attractive for public health programmes especially in regions of Africa where maternal HIV seroprevalence exceeds 5\%. ${ }^{3}$ However, the widespread use of antiretrovirals has been hindered by the lack of effective antenatal and delivery services, starting with proper HIV counselling and testing during pregnancy.

There is considerable evidence that exposure of the fetus to HIV in the maternal genital tract before and during delivery is an important route of vertical transmission. ${ }^{4}$ The first born twin is at higher risk of HIV infection than the second, ${ }^{5}$ prolonged rupture of membranes is associated with increased transmission, ${ }^{6}$ and there is a relation between viral load in the maternal genital tract and transmission risk. ${ }^{7}$ In neonates born to HIV-1 infected women receiving a long course prophylactic regimen of zidovudine, one third had detectable virus in the gastric aspirate. ${ }^{8}$ A similar observation has been made in Kenya in the absence of antiretrovirals. ${ }^{9}$ Elective caesarean section is an effective measure to reduce such transmission, but is not a reasonable option in most African settings because of the issues of cost, lack of personnel and infrastructures, and above all the high incidences of maternal morbidity and mortality. ${ }^{10}$ Therefore, there is a need for alternative means to decrease intrapartum exposure to HIV-1.

For these reasons, vaginal microbicides have been considered as a potential intervention to reduce MTCT. Vaginal microbicides may offer several advantages in resource-poor settings, besides the fact that they are inexpensive. They may have broader benefits from a public health point of view, independently of HIV infection, as studies performed in undustrialised countries demonstrated that the use of vaginal antiseptics can prevent perinatal and postpartum bacterial infections. ${ }^{11}$ However, two clinical trials performed in Malawi, ${ }^{12}{ }^{13}$ and Kenya ${ }^{14}$ failed to demonstrate the efficacy of vaginal disinfection with a chlorhexidine solution in reducing peripartum transmission of HIV.

Potential candidates for vaginal disinfection must inactivate HIV in vivo, be well tolerated and be available for self administration by women. Benzalkonium chloride (BC) has been shown to inactivate HIV in genital secretions. ${ }^{15}{ }^{16} \mathrm{BC}$ is not absorbed by mucosae and has therefore no systemic effect. When used intermittently as a spermicide, it has been shown to have no local toxic effect. ${ }^{17}$

We performed a phase II randomised placebo controlled clinical trial to evaluate the acceptability and tolerance of BC. Our research was conducted while the Malawi trial, ${ }^{11}{ }^{12}$ was the only completed trial on prevention of MTCT in Africathat is, before short antiretroviral regimens demonstrated their efficacy. We previously reported that BC, when used repeatedly in late pregnancy in this trial, was well tolerated in HIV infected pregnant women and in neonates and was also well accepted. ${ }^{18}$ The objective of the present report is to provide 15 month follow up data of the children enrolled in this trial with regard to MTCT of HIV-1 and child mortality.

\footnotetext{
${ }^{*}$ Members of the group are listed in the Appendix
} 


\section{MATERIAL AND METHODS}

Study setting and design of the Ditrame project, enrolment, treatment allocation, follow up procedures, and treatments tested in the Agence Nationale de Recherches sur le Sida (ANRS) 049b trial have been already described elsewhere. ${ }^{18} 19$ The enrolment was performed in neighbourhood maternal/ infant care units in the cities of Abidjan, Côte d'Ivoire, and Bobo-Dioulasso, Burkina Faso, from September 1996 to May 1997. The study protocol was approved by the ethics committees in Burkina Faso, Côte d'Ivoire, and France and by the scientific committee of the ANRS. In brief, women aged 18 years or more with confirmed HIV-1 positive serostatus who returned for post-test counselling were offered enrolment in the trial. Written consent was obtained individually, after the study objectives and content had been explained by a specially trained counsellor, in French or in a vernacular language.

Women self administered one daily vaginal capsule of either BC ( $1 \%$ concentration) or placebo from 36 weeks of pregnancy until labour. Another vaginal capsule (BC or placebo) was administered at the beginning of the delivery process in the maternity ward under supervision of the study team. Finally, the neonate was bathed with a BC solution (1\% concentration) or placebo within 30 minutes after birth, in the delivery room. The trial drugs, vaginal capsules, and bath powder were provided by Innothera Laboratory (Paris, France).

Women were followed weekly for tolerance and compliance visits from enrolment through delivery. ${ }^{18}$ After delivery, women and children were seen each month until 15 months after delivery/birth, and medical care was provided free of charge. Special attention was paid to counselling on infant feeding practices to reduce duration of breast feeding when possible. $^{20}$

\section{Study outcomes}

The outcome measures in the present analysis were HIV-1 infection and child mortality through 15 months. The diagnosis of paediatric HIV-1 infection was made on the basis of one positive polymerase chain reaction (PCR) test, according to international standards. ${ }^{21}$ All samples collected at 6 months, or earlier when not available, were systematically processed by a DNA (Abidjan) or RNA (Bobo-Dioulasso) PCR test. ${ }^{19}$ PCR was then applied to all the preceding available samples for a given child if the first one tested was positive, and the timing of transmission was estimated on the basis of the timing of the first positive test. ${ }^{21}$ Absence of infection was defined by a negative PCR on the latest available sample beyond the age of 3 months or by a negative serological test between 9 and 15 months of age. ${ }^{22}$ Those children who had no sample available for PCR and could not be followed beyond 6 months of age were considered of definitive unknown HIV status.

\section{Statistical analysis}

We chose the intent to treat approach for analysis. Group comparisons used Student's $t$ test or non-parametric MannWhitney test for quantitative variables, $\chi^{2}$ test, or Fisher's exact test for qualitative variables when appropriate. The probability of infection at a given age, breast feeding, and infant death were estimated using the Kaplan-Meier survival technique and comparisons used the log rank test. For the analysis of risk factors of MTCT HIV transmission, we excluded the second child in each pair of liveborn twins. We used as explanatory variables sociodemographic characteristics of the women (age, gestation, and parity) and CD4 lymphocyte count collected at enrolment, duration of labour and rupture of membranes, birth weight and gestational age at birth. All these data were used in a Cox multivariate proportional hazards model to study BC relative efficacy, expressed as one minus the hazard ratio (HR) of the transmission rate in the $\mathrm{BC}$ arm versus the transmission rate in the placebo arm. Point estimates of summary statistics are reported with their 95\% confidence interval (CI). The same approach was also used to look for determinants of infant mortality.

\section{RESULTS}

Of the total of 107 HIV infected women enrolled, 53 were allocated to the BC group and 54 to the placebo group. Maternal age (mean 24.6 years), parity (mean 1.8), education level, marital status, clinical characteristics, and distribution of CD4 lymphocyte counts (mean $58910^{6} / 1$ ) at baseline were balanced between the two groups. In both groups, the mean duration of antenatal treatment was 3 weeks and $97 \%$ of the mothers delivered in the hospital maternity unit.

A total of 111 children were born, including four sets of twins (two in each treatment group). There were 107 livebirths and four stillbirths (one in the BC group and three in the placebo group, all singletons). Stillbirths were excluded from the transmission study as well as the second twins. Thus, 103 children were eligible for this analysis. Mean birth weight was $2845 \mathrm{~g}$, the percentage of low birth weight $(<2500 \mathrm{~g})$ was $20 \%$, and prematurity rate ( $<37$ weeks of pregnancy) was $7.2 \%$ without differences between the two groups. The median follow up of the children was 450 days in both groups. The median duration of breast feeding was 324 days without differences between the two groups.

Five children remained of indeterminate status for HIV infection (two died at day 2 and day 57, respectively and three were lost to follow up at day 1 , day 7 , and day 34, respectively, before any interpretable blood sample was available). Three of these were in the BC group and two in the placebo group. At 15 months of follow up, 11 children were diagnosed as HIV infected in the BC group and 12 in the placebo group (table 1). The probability of transmission of HIV was $20.4 \%$ and $21.0 \%$ at 6 months of age in placebo and BC group respectively and $24.8 \%$ and $23.5 \%$ at 15 months of age. There was no significant difference between the two treatment groups (log rank test, $\mathrm{p}=0.84$ ). There was no difference between the transmission rates in the two trial sites (data not shown). The transmission rate differed significantly according to maternal immune status $(40.5 \%$ among mothers with CD4 lymphocytes counts below $500 \times 10^{6} /$, versus $10.7 \%$ among those with counts of $500 \times 10^{6} / 1$ or more, $\mathrm{p}=0.001$ ).

In the multivariate analysis of risk factors for HIV transmission, none of the factors studied was significantly associated with the infection status of the infants: trial arm, study site, birth weight, gestational age, maternal age, number of previous pregnancies, maternal CD4 lymphocyte count, duration of membrane rupture. For maternal CD4 lymphocyte counts, the hazard ratio for HIV transmission was 0.88 for each increase of $100 \mathrm{CD} 4 \times 10^{6} / 1(95 \%$ CI: 0.729 to 1.068 ; $\mathrm{p}=0.20)$.

Overall mortality at 15 months was 10 of 55 infants in BC group and six of 56 in the placebo group, in addition to two and three stillbirths, respectively (table 2 ). The difference in mortality over the study period was not significantly different between the two treatment arms (log rank test, $\mathrm{p}=0.31$ ). Perinatal mortality (stillbirths and early neonatal deaths in the first week of life) was 5.5\% in the BC group and $5.4 \%$ in the placebo group, $(p=0.49)$. Twelve of the 17 children who died during the first 15 months of follow up were HIV infected; the causes of death were lower respiratory tract infections (six), meningitis or encephalitis (three), diarrhoea (two), and unknown cause (one). There were three deaths among uninfected infants, one neonatal death related to intrapartum asphyxia and two cases of meningitis. Two children died with indeterminate HIV infection status, one of intrapartum asphyxia at day 2 and the other of lower respiratory infection at day 57. HIV free survival probability at 15 months ( 1 - the risk of HIV infection or death) was $77.6 \%$ in the placebo group versus $74.9 \%$ in the $\mathrm{BC}$ group (log rank test $\mathrm{p}=0.79$ ). 
Table 1 Mother to child transmission (MTCT) rates of HIV-1 through 15 months of age by treatment group. Ditrame ANRS 049b trial. Abidjan, Côte d'Ivoire and Bobo-Dioulasso, Burkina Faso, 1996-8

\begin{tabular}{llll}
\hline Time point & Birth & 6 months & 15 months \\
\hline $\begin{array}{l}\text { Cumulative number of children infected } \\
\text { Benzalkonium chloride group }\end{array}$ & 3 & 10 & 11 \\
$\quad \begin{array}{l}\text { Placebo group } \\
\text { Probability of MTCT transmission \% (Cl)* }\end{array}$ & 1 & 10 & 12 \\
$\quad$ Benzalkonium chloride group & $6.1(2.0$ to 17.8$)$ & $21.0(12.0$ to 35.6$)$ & $23.5(13.8$ to 38.5$)$ \\
$\quad$ Placebo group & $2.0(0.3$ to 13.6) & $20.4(11.6$ to 34.6) & $24.8(15.0$ to 39.6$)$ \\
\hline Cl : 95\% confidence interval. & & & \\
*Calculated by Kaplan-Meier method. & & & \\
\hline
\end{tabular}

Table 2 Infant mortality (including stillbirths) and risk of death to the age of 15 months. Ditrame ANRS $049 \mathrm{~b}$ trial. Abidjan, Côte d'Ivoire and Bobo-Dioulasso, Burkina Faso, 1996-8

\begin{tabular}{|c|c|c|c|c|c|}
\hline Time point & $\begin{array}{l}\text { Day } 0 \\
\text { (stillbirths) }\end{array}$ & $\begin{array}{l}1 \text { week (early } \\
\text { neonatal mortality) }\end{array}$ & $\begin{array}{l}1 \text { month } \\
\text { (neonatal mortality) }\end{array}$ & $\begin{array}{l}1 \text { year } \\
\text { (infant mortality) }\end{array}$ & 15 months \\
\hline \multicolumn{6}{|l|}{ Cumulative number of deaths } \\
\hline Benzalkonium chloride group & 2 & 4 & 4 & 11 & 12 \\
\hline Placebo group & 3 & 3 & 3 & 9 & 9 \\
\hline \multicolumn{6}{|l|}{ Likelihood of dying (\%)* } \\
\hline Benzalkonium chloride group* & - & 5.5 (1.8 to 16.0$)$ & 7.3 (2.9 to 18.3$)$ & 20.8 (12.1 to 34.4$)$ & 22.9 (13.7 to 36.9 ) \\
\hline Placebo group* & - & 5.4 (1.8 to 15.7$)$ & 5.4 (1.8 to 15.7$)$ & $16.5(9.0$ to 29.4$)$ & 16.5 (9.0 to 29.4$)$ \\
\hline
\end{tabular}

In the Cox model for risk factors for infant mortality, the only factor associated with the risk of death by 15 months was HIV infection of the child (hazard ratio: $16.7,95 \%$ CI: 4.8 to 58.4). Age of the mother, number of previous pregnancies, maternal CD4 lymphocyte count, birth weight, low gestational age, duration of rupture of membranes, site of the study, and trial arm were not associated with the risk of child death.

\section{DISCUSSION}

In this randomised clinical trial, we failed to demonstrate a difference in mother to child HIV transmission after vaginal cleansing and neonatal bathing with $\mathrm{BC}$, compared to placebo. However, this trial was designed as a phase II, and therefore the sample size was too small to rule out a clinically significant treatment difference between the two groups. None the less, the transmission rate in both groups was of the same order of magnitude as that observed in the placebo arm of the Ditrame/ANRS 049a trial, which was conducted in the same study sites. ${ }^{19} 23$ In this study, which evaluated the efficacy of short course zidovudine, the transmission rates in the absence of zidovudine were $27.5 \%$ at 6 months of age and $30.6 \%$ at 12 months. To date, there are no clinical data suggesting the efficacy of vaginal microbicide use in decreasing mother to child HIV transmission. In large clinical trials evaluating vaginal disinfection with chlorhexidine in Malawi and Kenya, ${ }^{11}{ }^{13}$ no reduction in transmission was observed. However, the interventions were performed in advanced labour, possibly too late to inactivate the virus and eliminate it from the birth canal. Although the rationale for our intervention was to begin the use of the vaginal microbicide well before the onset of labour or membrane rupture, we did not find evidence of any benefit in reducing transmission.

Furthermore, in our study, BC did not appear to reduce the rate of infant mortality, including during the perinatal period. The distressingly high mortality we observed was in the same range as that reported in the infant feeding trial from Nairobi $^{24}$ and the causes of death were the same as in other African cohorts of children born to HIV infected women. ${ }^{25} 26$ As mentioned above, the statistical power of our study may not have been sufficient to detect a benefit in terms of mortality, but there was not even a trend suggesting that the intervention may be useful. Furthermore, the majority of deaths occurred in HIV infected children, beyond the neonatal period. Finally, the babies in the placebo group were bathed at birth with water containing no $\mathrm{BC}$, which was not done in previous studies. The hypothesis that bathing, even without adding an antiseptic, may have a beneficial effect on neonatal infectious morbidity has not been evaluated, but could be speculated.

Although our study failed to demonstrate any beneficial effect of vaginal cleansing with $\mathrm{BC}$, we believe that further research on vaginal microbicides in pregnancy is warranted. In this trial, we previously demonstrated that $\mathrm{BC}$, used in vaginal capsules for a median of 3 weeks in late pregnancy and in a neonatal bath, was well tolerated by HIV infected pregnant women and their neonates. ${ }^{17}$ The feasibility and acceptability were good in both west African cities. Antiseptics such as benzalkonium chloride, as well as new microbicides presently in preliminary research phases, have the potential to decrease perinatal, neonatal, and maternal morbidity and mortality. ${ }^{10}$ In the Malawi study, chlorhexidine use was associated with significant decreases in postpartum fever in mothers and perinatal mortality in children. ${ }^{13}$ Further clinical trials may be considered to evaluate the efficacy of other vaginal microbicides in reducing perinatal infectious morbidity, beyond the specific issue of mother to child HIV transmission and the crude outcome of infant mortality. Any such intervention should be evaluated in addition to prevention of MTCT using antiretroviral drugs, which have proved efficacy in decreasing mother to child HIV transmission, and should therefore be considered today as the standard of care. ${ }^{3}$ The place for vaginal microbicides may be as part of a public health package, including STD management, malaria, and anaemia prevention in rural Africa, where access to HIV testing and antiretroviral chemoprophylaxis is limited and is likely to remain difficult to implement for many years.

\section{APPENDIX}

The ANRS 049 Group is organised as follows: Biostatistics: L Dequa-Merchadoux ${ }^{3}, \mathrm{R}$ Lassalle ${ }^{3}, \mathrm{~V}$ Leroy $^{3}, \mathrm{R}$ Salamon ${ }^{3}$. Epidemiology: M Cartoux ${ }^{2}, \mathrm{~F}$ Dabis $^{3}$ (coordinator of the ANRS 049 
trial/Ditrame programme), N $\mathrm{Meda}^{2}$ (coordinator of BoboDioulasso Center), P Msellati $^{1}$ (coordinator of Abidjan Center), R Ramon ${ }^{1}$.Gynaecology-Obstetrics: A Bazié2, B Dao², R Likikouet ${ }^{1}$, L Mandelbrot ${ }^{4}$ (principal investigator), C Welffens-Ekra ${ }^{1}$ (principal investigator). Microbiology: D Bonard ${ }^{1}, \mathrm{P}^{2}$ Combe ${ }^{1}, \mathrm{M}$ Dosso' ${ }^{1}$, L Gautier-Charpentier ${ }^{2}$, FD Ky ${ }^{2}$, A Ouangré2, T Ouassa', O Sanou ${ }^{2}$, F Sylla-Koko', Y Traore ${ }^{2}$, P Van de Perre ${ }^{2}$. Molecular biology: AM Cassel-Beraud ${ }^{2}, \mathrm{JB} \mathrm{Kottan}^{1}, \mathrm{O}$ Manigart $^{2}, \mathrm{C}$ Montcho $^{1}$, C Rouzioux ${ }^{4}$, A Simonon ${ }^{2}$, D Valea ${ }^{2}$, B You'. Paediatrics: $\mathrm{R}$ Camara ${ }^{1}, \mathrm{~N}$ Elenga $^{1}, \mathrm{~B} \mathrm{Nacro}^{2}, \mathrm{~F}$ Tall ${ }^{2}, \mathrm{M}^{2}$ Timité $^{1}$. Trial

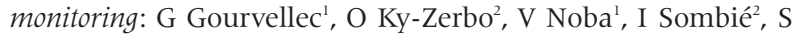
Tiendrebeogo ${ }^{2}$, I Viho', $\mathrm{S}_{\text {Yaro }}^{2}$.

Abidjan health facilities: Anonkoua-Koute, Ouassakara, Yopougon and Yopougon-Attie, Centre Hospitalier Universitaire de Yopougon.

Bobo-Dioulasso health facilities: Accart-Ville, Farakan and Social Security, Centre Hospitalier National Souro Sanou.

1 Abidjan Centre, 2 Bobo-Dioulasso Centre, 3 Bordeaux Coordination Unit, 4 Paris.

\section{ACKNOWLEDGEMENTS}

The ANRS 049/Ditrame project was funded by the French Agence Nationale de Recherches sur le SIDA (ANRS) and the French Ministry of Cooperation (Action Coordonnée no 12).

Presented in part at the Conference "Microbicides 2000," Washington DC, USA, 13-16 March 2000 (abstract S71).

The authors wish to thank the nurses and counsellors working with the Ditrame project and the staff from the participating prenatal care and delivery unit for their daily compassionate work. Special thanks to Drs MA Nandeuil, M Mathieu, and C Meignant (Innothéra, France) for assisting in the preparation of the trial, especially drug supply, packaging, and shipping.

\section{CONTRIBUTORS}

LM was one of the primary investigators, wrote the protocol and the final version of the manuscript; PM wrote the protocol, the first versions of the manuscript, and was the coordinator of the Abidjan centre; NM wrote the protocol and was the coordinator of the Bobo-Dioulasso centre; VL was in charge of statistical analysis and methodological aspects; RL was the obstetrician in charge for the follow up of the women in Abidjan; PVdP contributed to the design and conduct of the research and directed all biological aspects of the project; LD-M was the data manager and participated in the statistical analysis; FS-K and TO supervised and analysed biological laboratory activities in Abidjan; AO supervised all laboratory activities in Bobo-Dioulasso; RR was the data manager and epidemiological supervisor for Abidjan; LG-C supervised all immunological aspects of the project in Bobo Dioulasso; MC contributed to designing and organising antenatal HIV screening procedures; MD directed the microbiological testing in Abidjan; FD was the Ditrame programme coordinator, wrote the protocol, supervised the research; CW-E was one of the obstetrician principal co-investigators.

\section{Authors' affiliations}

L Mandelbrot, Maternité Port Royal, Hopital Cochin, Paris, France P Msellati, UR091, Institut de Recherche pour le Développement (IRD)/LPE, Marseille, France

N Meda, P Van de Perre, FA Ouangre, L Gautier-Charpentier, M Cartoux, Centre Muraz, Bobo Dioulasso, Burkina Faso

V Leroy, L Dequae-Merchadoux, F Dabis, INSERM U. 330, Université Victor Segalen Bordeaux 2, Bordeaux, France R Likikouët, Sylla-Koko, T Ouassa, R Ramon, Programme PAC-Cl, CHU de Treichville, Abidjan, Côte d'Ivoire

M Dosso, Département de Microbiologie, Institut Pasteur de Côte d'Ivoire, Ábidjan

C Welffens-Ekra, Département de Gynécologie Obstétrique, $\mathrm{CHU}$ de Youpougon, Abidjan, Côte d'lvoire

\section{REFERENCES}

1 Mofenson LM, Mc Intyre JA. Advances and research directions in the prevention of mother-to-child HIV-1 transmission. Lancet 2000:355:2237-44

2 Wiktor S, Leroy V, Ekpini ER, et al. 24-Month efficacy of short-course maternal zidovudine for the prevention of mother-to-child HIV-1 transmission in a breast feeding population: a pooled analysis of two randomized clinical trials in West Africa. XIII International AIDS Conference. Durban, South Africa, 9-14 July 2000 (TuOrB354).

3 Dabis F, Leroy V, Castetbon K, et al. Preventing mother-to-child transmission of HIV-1 in Africa in the year 2000. AIDS 2000;14:1017-24

4 Van de Perre P, Meda N. Interventions to reduce mother to child transmission of HIV-1. AIDS 1995;9(suppl A):S59-66

5 Duliège, $\mathrm{AM}$, Amos $\mathrm{Cl}$, Felton $\mathrm{S}$, et al, International Registry of HIV-Exposed Twins. Birth order, delivery route and concordance in the transmission of human immunodeficiency virus type 1 from mothers to twins. J Pediatr 1995;126:625-32.

6 The International Perinatal HIV Group. Duration of ruptured membranes and vertical transmission of HIV-1:a meta-analysis from 15 prospective studies. AIDS 2001:15:357-68.

7 Chuachoowong $\mathbf{R}$, Shaffer N, Siriwasin W, et al. Short-course antenatal zidovudine reduces both cervicovaginal human immunodeficiency virus type 1 RNA levels and risk of perinatal transmission. Bangkok Collaborative Perinatal HIV Transmission Study Group. J Infect Dis 2000:181:99-106

8 Mandelbrot L, Burgard M, Teglas JP, et al. Frequent detection of HIV-1 in the gastric aspirates of neonates born to HIV-infected mothers. AIDS in the gastric aspira
$1999 ; 13: 2143-9$.

9 Gaillard P, Verhofstede C, Mwanyumba F, et al. Exposure to HIV-1 during delivery and mother to child transmission. AIDS 2000;14:2341-8.

10 Graham WJ, Newell ML. Seizing the opportunity: collaborative initiatives to reduce HIV and maternal mortality. Lancet 1999;353:836-9

11 Burman L, Christensen P, Christensen K, et al. Prevention of excess neonatal morbidity associated with group $B$ streptococci by vaginal chlorhexidine disinfection during labour. Lancet 1992;340:65-9.

12 Biggar RJ, Miotti PG, Taha TA, et al. Perinatal intervention trial in Africa: effect of a birth canal cleansing intervention to prevent HIV transmission. Lancet 1996;347:1647-50.

13 Taha ET, Biggar RJ, Broadhead RL, et al. Effect of cleansing the birth canal with antiseptic solution on maternal and newborn morbidity and mortality in Malawi: clinical trial. BM 1997;315:216-9.

14 Gaillard P, Mwanyumba F, Verhofstede C, et al. Vaginal lavage with chlorhexidine during labour to reduce mother to child HIV transmission:clinical trial in Mombasa, Kenya. AIDS 2001;15:389-96.

15 Sattar SA, Springthorpe VS. Survival and disinfectant inactivation of the Human Immunodeficiency Virus: a critical review. Rev Infect Dis 1991; 13:430-47

16 Wainberg MA, Spira B, Bleau G, et al. Inactivation of Human Immunodeficiency Virus Type 1 in tissue culture fluid and in genital secretions by the spermicide benzalkonium chloride. J Clin Microbiol 1990;28:156-8.

17 Erny R, Sibody C. Les tampons au chlorure de benzalkonium:tolérance locale et effet sur la glaire cervicale. J Gynécol Obstét Biol Reprod 1983; 12:767-74

18 Msellati P, Meda N, Leroy V, et al. Safety and acceptability of vaginal disinfection with benzalkonium chloride in HIV-infected pregnant women in West Africa:ANRS $049 \mathrm{~b}$ phase II randomized, double blinded placebo-controlled trial. Sex Transm Infect 1999;75:420-5.

19 Dabis F, Msellati P, Méda N, et al. Six month efficacy, tolerance and acceptability of a short regimen of oral zidovudine in reducing vertical transmission of HIV in breast-fed children:A double-blind placebo controlled multicentre trial, ANRS 049a, Côte d'Ivoire and Burkina Faso. Lancet 1999;353:786-92.

20 Msellati P, Meda N, Welffens-Ekra C, et al. Zidovudine and reduction of HIV vertical transmission in Africa. Am J Public Health 1999;89:946-7.

21 Dabis F, Msellati $P$, Newell M-L, et al. Methodology of interventions trials to reduce mother to child transmission of HIV with special reference to developing countries. AIDS 1995;9(suppl A):S67-74

22 Dabis F, Msellati P, Dunn D, et al. Estimating the rate of mother-to-child transmission of HIV. Report of a workshop on methodological issues, Ghent (Belgium), 17-20 February 1992. AIDS 1993;7:1139-48.

23 Ditrame ANRS 049 Study Group. 15 month-efficacy of maternal oral zidovudine to decrease vertical transmission of HIV-1 in breastfed African children. Lancet 1999;354:2050-1.

24 Nduati R, John G, Mbori-Ngacha D, et al. Effect of breastfeeding and formula feeding on transmission of HIV-1. A randomized clinical trial. JAMA 2000;283: 1 167-74.

25 Spira R, Lepage $P$, Msellati $P$, et al. Natural history of human immunodeficiency virus type 1 infection in children: a five-year prospective study in Rwanda. Pediatrics 1999;104:e56.

26 Dabis F, Elenga N, Meda N at al. 18-Month mortality and perinatal exposure to zidovudine in West Africa. AIDS 2001;15:771-9. 